\title{
Significance and Function of MicroRNA-7 in Oesophageal Squamous Cell Carcinoma
}

\author{
KEIGO HARA, TATSUYA MIYAZAKI, TAKEHIKO YOKOBORI, TOMONORI YOSHIDA, YUJI KUMAKURA, \\ HIROAKI HONJYO, MAKOTO SAKAI, MAKOTO SOHDA, MINORU FUKUCHI and HIROYUKI KUWANO \\ Department of General Surgical Science, Graduate School of Medicine, \\ Gunma University, Maebashi, Japan
}

\begin{abstract}
Background/Aim: We detected microRNA-7 (miR7) as being specific for oesophageal squamous cell carcinoma (ESCC) by using database analysis. However, the significance of miR-7 in clinical ESCC remains unexplored. This study aimed to clarify the clinicopathological significance of miR-7 in ESCC, and investigate miR-7 function. Materials and Methods: Quantitative TaqMan reverse transcription polymerase chain reaction was used to evaluate miR-7 expression in 85 ESCC samples to determine the clinicopathological significance of miR-7 expression. The regulation of proliferation by miR-7 was examined with miR7 precursor-transfected cells. Results: The expression of miR-7 in ESCC was higher than that in normal tissues. Low expression levels of miR-7 were associated with poor prognosis. Multivariate analysis indicated that low miR-7 expression was an independent prognostic factor for poor survival. In vitro assays showed miR-7 precursor treatment suppressed the proliferation of ESCC cells. Conclusion: miR7 might be a promising prognostic marker and therapeutic target in ESCC.
\end{abstract}

Survival of patients with advanced oesophageal squamous cell carcinoma (ESCC) remains poor regardless of improvements in perioperative management and definitive and adjuvant therapy (1-3). Locally advanced ESCC directly invades adjacent organs; this increases local recurrence and makes radical surgical resection difficult. Moreover, such ESCC cases exhibit early lymphatic and frequent haematogenous dissemination compared with other types of gastrointestinal cancer $(4,5)$. Therefore, markers that can predict ESCC

Correspondence to: Tatsuya Miyazaki, MD, Ph.D., Department of General Surgical Science, Graduate School of Medicine, Gunma University, 3-39-22, Showamachi, Maebashi 371-8511, Japan. Tel: +81 0272208224, Fax: +81 0272208230, e-mail: tatsuyamiyazaki@gunmau.ac.jp

Key Words: microRNA, oesophageal cancer, prognostic marker. progression and prognosis correctly and reliably are needed for improving survival of patients with ESCC.

MicroRNAs (miRs) have attracted attention as important regulators of gene expression. These small non-coding RNAs are 18-25 nucleotides in length and partially bind to the 3'untranslated region of target mRNAs. This binding of miR and mRNA leads to mRNA degradation or translational repression (6). Depending on their targets, many miRs play important roles in proliferation, apoptosis, differentiation, and cancer progression. In order to find cancer-specific miRs in ESCC, we re-analyzed data with the series accession number GSE6188 in the Gene Expression Omnibus public microarray database (7). As a result, we detected $m i R-196 a$, $m i R-7$, and $m i R-503$ as being up-regulated by $6.64-, 4.31-$ and 3.65-fold, respectively, in ESCC compared to normal oesophageal mucosa. The function and expression significance of $m i R-196 a$ and $m i R-503$ in ESCC have been reported (8-10). In addition, $\mathrm{Fu}$ et al. reported that the expression level of $m i R-7$ in primary ESCC tissue was higher than that in non-cancerous tissues (11), and Dong et al. described serum $m i R-7$ expression in patients with ESCC as being higher than that in healthy volunteers (12). However, few studies are available on the significance and function of miR-7 expression in ESCC.

The purpose of this study was to clarify the clinicopathological significance of $m i R-7$ expression in ESCC, and to investigate the function of $m i R-7$ in ESCC cells in vitro. Therefore, we examined the expression of $m i R-7$ in clinical ESCC samples and the miR-7-mediated regulation of proliferation in ESCC cells in vitro.

\section{Materials and Methods}

Cancer-specific miR detection by re-analysis of GSE6188. Reanalysis for GSE6188 was performed by Subio Platform (Subio Inc. Tokyo, Japan). Probes significantly different between cancerous tissues (153 samples) and normal tissues (104 samples) were extracted with a fold-change greater than 3.5 and a $t$-test (equal variance) with $p<0.05$. The probes corresponding to over half of 48 donors with two cancerous tissues and two adjacent normal tissues 
and whose clinical characteristics were significantly different were selected as the three up-regulated miRs.

Clinical samples and RNA isolation. Samples of primary ESCC $(\mathrm{n}=85)$ and corresponding normal oesophageal epithelium $(n=85)$ were obtained from patients with ESCC who had undergone potentially curative surgery at the Department of General Surgical Science, Gunma University, Japan, between 1999 and 2006. These samples were used after obtaining written informed consent in accordance with institutional guidelines and the Declaration of Helsinki (approval number 1457). The pathological features of the samples were classified according to the sixth edition of the TNM Classification of the International Union against Cancer (13). The surgical procedures were classified as curative; there was no evidence of residual tumour tissue, and the resected margins were microscopically free of tumour (R0). Normal tissue samples were obtained away from the centre of the tumour in surgical specimens. All samples were immediately frozen in liquid nitrogen and stored at $-80^{\circ} \mathrm{C}$ until RNA extraction. Total RNA was extracted using the miRNeasy Mini kit (Qiagen, Hilden, Germany) according to the manufacturer's instructions.

Evaluation of miR-7 expression in clinical ESCC samples. For quantitative real-time reverse transcriptase-polymerase chain reaction (RT-PCR) of $m i R-7$, cDNA was synthesized from $10 \mathrm{ng}$ total RNA using the TaqMan MicroRNA Reverse Transcription kit and specific stem-loop reverse transcription primers (Applied Biosystems, Foster city, CA, USA) according to the manufacturer's protocol. PCR was performed in a LightCycler ${ }^{\mathrm{TM}} 480$ system (Roche Diagnostics GmbH, Mannheim, Germany). The $20 \mu \mathrm{l} \mathrm{PCR}$ mixture included in the LightCycler 480 Probes Master kit (Roche Diagnostics GmbH, Mannheim, Germany) was incubated in a 96 well optical plate at $95^{\circ} \mathrm{C}$ for $10 \mathrm{~min}$, and then subjected to 45 cycles of $95^{\circ} \mathrm{C}$ for 10 seconds and $60^{\circ} \mathrm{C}$ for $30 \mathrm{sec}$. Expression levels of $m i R-7$ were normalized to that of the small nuclear RNA $R N U 6 B$ and analysed using the $2^{-\Delta \Delta C t}$ method.

Cell line. The human ESCC cell line TE- 8 was obtained from the RIKEN BioResource Center (RIKEN BRC, Tukuba, Ibaraki, Japan). TE-8 cells were cultured in RPMI_1640 medium (Wako, Osaka, Japan) supplemented with $10 \%$ foetal bovine serum and $1 \%$ penicillin-streptomycin antibiotics (Invitrogen, Carlsbad, CA, USA).

Transfection of the miR-7 precursor. Pre-miR ${ }^{\mathrm{TM}}$ miRNA Precursor Molecule mimicking miR-7 (premiR-7; Applied Biosystems) or nonspecific control miR (Pre-miR ${ }^{\mathrm{TM}}$ miRNA Negative Control \#1; premiR-nc; Applied Biosystems) was transfected at $30 \mathrm{pmol} / \mathrm{l}$ into TE- 8 cells by using an electroporator (CUY 21 EDIT II; BEX, Tokyo, Japan) according to protocol. Before conducting assays, we confirmed that miR-7 expression in premiR-7 precursor-treated cells was significantly higher than that in the parent TE- 8 cells and control miR-treated cells using RT-PCR.

Proliferation assay. Cell proliferation analysis was performed using cells that had been transfected with negative control or premiR-7. The cells were plated in 96-well plates in $100 \mu \mathrm{l}$ of medium at approximately 3,000 cells per well. For the quantification of cell viability in the WST-8 assay (Dojindo Lab., Tokyo, Japan), $10 \mu \mathrm{l}$ of the cell counting solution was added to each well after $0,24,48$, and $72 \mathrm{~h}$ and plates were incubated at $37^{\circ} \mathrm{C}$ for another 2 hours. The cell proliferation rate was then determined by measuring the

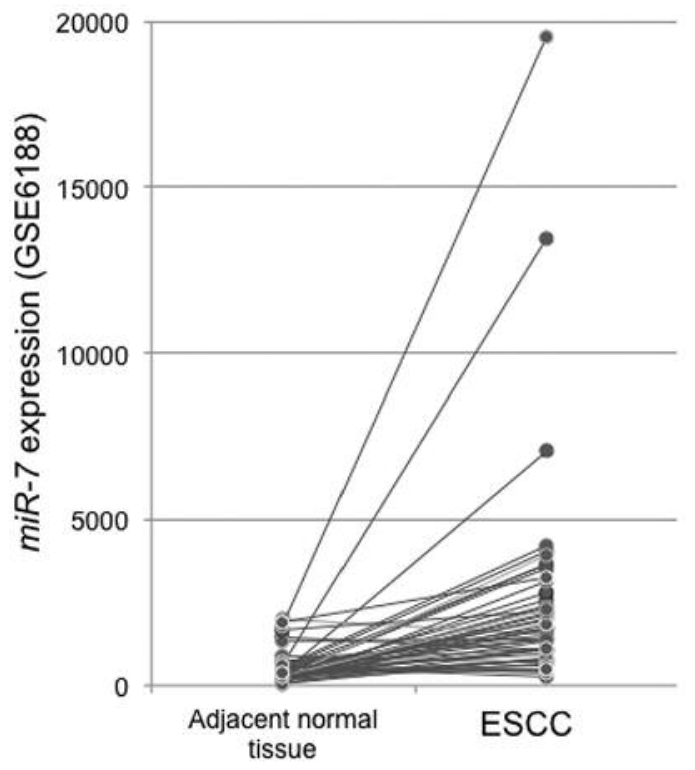

Figure 1. Clinical significance of miR-7 expression in oesophageal squamous cell carcinoma (ESCC) samples from the re-analysed GSE6188 data. miR-7 levels were shown to be higher in ESCC than those of the adjacent normal tissues.

absorbance of the well at $450 \mathrm{~nm}$ with the reference wavelength set at $650 \mathrm{~nm}$. Absorbance was read using a microtitre plate reader (Molecular Devices, Sunnyvale, CA, USA).

Statistical analysis. Differences between groups were estimated using Student's $t$-test, the chi-square test, and the repeated measures ANOVA. Kaplan-Meier curves were generated for overall survival, and statistical significance was determined using the log-rank test. A probability value of less than 0.05 was considered significant. All statistical analyses were performed using JMP software (SAS Institute, Cary, NC, USA).

\section{Results}

Clinical significance of $m i R-7$ expression in patients with ESCC. Re-analysis of GSE6188 revealed miR-196a, miR-7 and $m i R-503$ to be up-regulated in ESCC Among them, we focused on $m i R-7$ (Figure 1) in order to clarify the clinical significance of $m i R-7$ expression in clinical ESCC samples. We assessed $m i R-7$ expression in $85 \mathrm{ESCC}$ samples and 85 paired noncancerous samples. The expression of $m i R-7$ was significantly greater in tumour than in normal tissue $(p<0.001)$ (Figure 2A).

We divided the 85 patients with ESCC into two groups according to the tumour/normal tissue ratio $(\mathrm{T} / \mathrm{N})$ for $m i R-7$ expression, and the cut-off point was defined as $\mathrm{T} / \mathrm{N}=8.5$ (high-expression group, $\mathrm{T} / \mathrm{N} \geq 8.5, \mathrm{n}=31$; low-expression group, $\mathrm{T} / \mathrm{N}<8.5, \mathrm{n}=54$ ). Clinicopathological factors did not differ between the miR-7 low-expression and high-expression groups (Table I). 


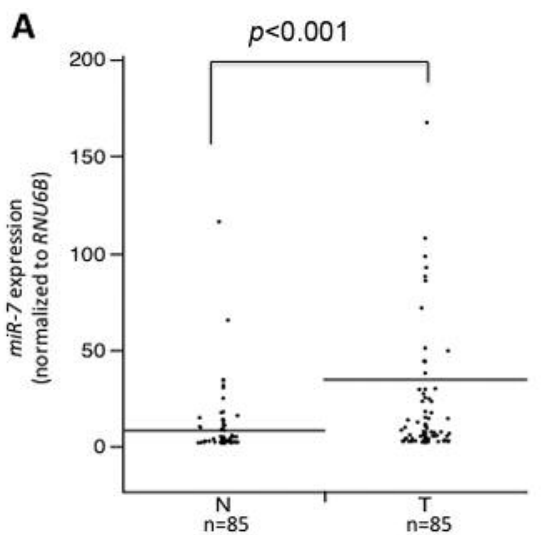

B

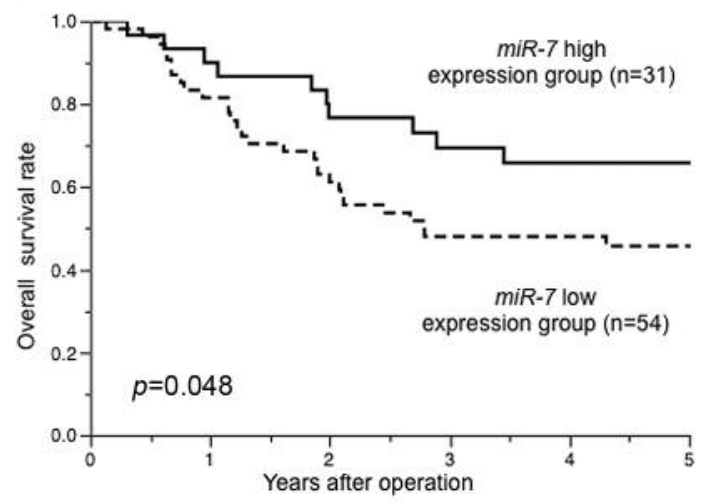

C

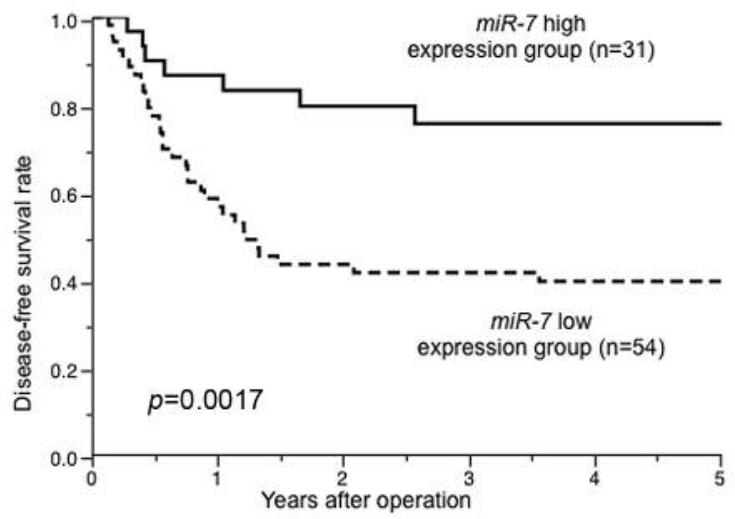

Figure 2. miR-7 expression in 85 oesophageal squamous cell carcinoma (ESCC) samples of our cohort and its relationship with survival. A: The expression levels of miR-7 in tumour $(T)$ and normal $(N)$ tissue. Overall $(B)$ and disease-free $(C)$ survival curves of patients with ESCC according to miR-7 expression using a cut-off of 8.5.

Prognostic significance of miR-7 expression in patients with $E S C C$. The overall survival curve revealed that patients in the low-miR-7 expression group had a significantly poorer prognosis than those in the high-expression group $(\mathrm{p}=0.048)$ (Figure 2B). In univariate and multivariate analyses, low
Table I. Relationship between miR-7 expression and clinicopathological features.

\begin{tabular}{|c|c|c|c|}
\hline \multirow[b]{2}{*}{ Factors } & \multicolumn{2}{|c|}{$m i R-7 / R N U 6 B$} & \multirow[b]{2}{*}{$p$-Value } \\
\hline & $\begin{array}{c}\text { Low expression } \\
\mathrm{n}=54\end{array}$ & $\begin{array}{l}\text { High expression } \\
\quad n=31\end{array}$ & \\
\hline \multicolumn{4}{|l|}{ Age } \\
\hline$<65$ Years & 22 & 14 & \multirow[t]{2}{*}{0.72} \\
\hline$\geq 65$ Years & 26 & 14 & \\
\hline \multicolumn{4}{|l|}{ Gender } \\
\hline Male & 47 & 29 & \multirow[t]{2}{*}{0.34} \\
\hline Female & 7 & 2 & \\
\hline \multicolumn{4}{|l|}{$\mathrm{T}$ Factor } \\
\hline $\mathrm{T} 1$ & 12 & 7 & \multirow[t]{2}{*}{0.96} \\
\hline $\mathrm{T} 2, \mathrm{~T} 3, \mathrm{~T} 4$ & 42 & 24 & \\
\hline \multicolumn{4}{|l|}{ N Factor } \\
\hline Absent & 17 & 10 & \multirow[t]{2}{*}{0.94} \\
\hline Present & 37 & 21 & \\
\hline \multicolumn{4}{|c|}{ Lymphatic invasion } \\
\hline Absent & 5 & 1 & \multirow[t]{2}{*}{0.29} \\
\hline Present & 49 & 30 & \\
\hline \multicolumn{4}{|c|}{ Venous invasion } \\
\hline Absent & 8 & 8 & \multirow[t]{2}{*}{0.21} \\
\hline Present & 46 & 23 & \\
\hline \multicolumn{4}{|l|}{ M Factor } \\
\hline Absent & 44 & 26 & \multirow[t]{2}{*}{0.78} \\
\hline Present & 10 & 5 & \\
\hline Stage & & & 0.43 \\
\hline 1 & 8 & 3 & \\
\hline 2 & 15 & 14 & \\
\hline 3 & 20 & 9 & \\
\hline 4 & 11 & 5 & \\
\hline
\end{tabular}

expression of $m i R-7$ in ESCC was found to be a significant independent prognostic factor (Table II). In multivariate analysis, other investigated clinicopathological factors were not revealed as significant independent predictors of poor prognosis in this ESCC cohort, whereas low expression of $m i R-7$ in primary ESCC remained prognostically significant with regard to overall survival.

Regulation of proliferation by miR-7 in ESCC cells. We confirmed that the expression of $m i R-7$ in $m i R-7$ precursortransfected cells was higher than that in control cells (Figure 3A). Proliferation of $m i R-7$ precursor-transfected cells was significantly reduced from $48 \mathrm{~h}$ compared with control cells $(p<0.05)$ (Figure 3B).

\section{Discussion}

In this study, we clarified that a low expression level of $m i R-7$ in ESCC was an independent prognostic factor in spite of cancer-specific high expression and weak association with 

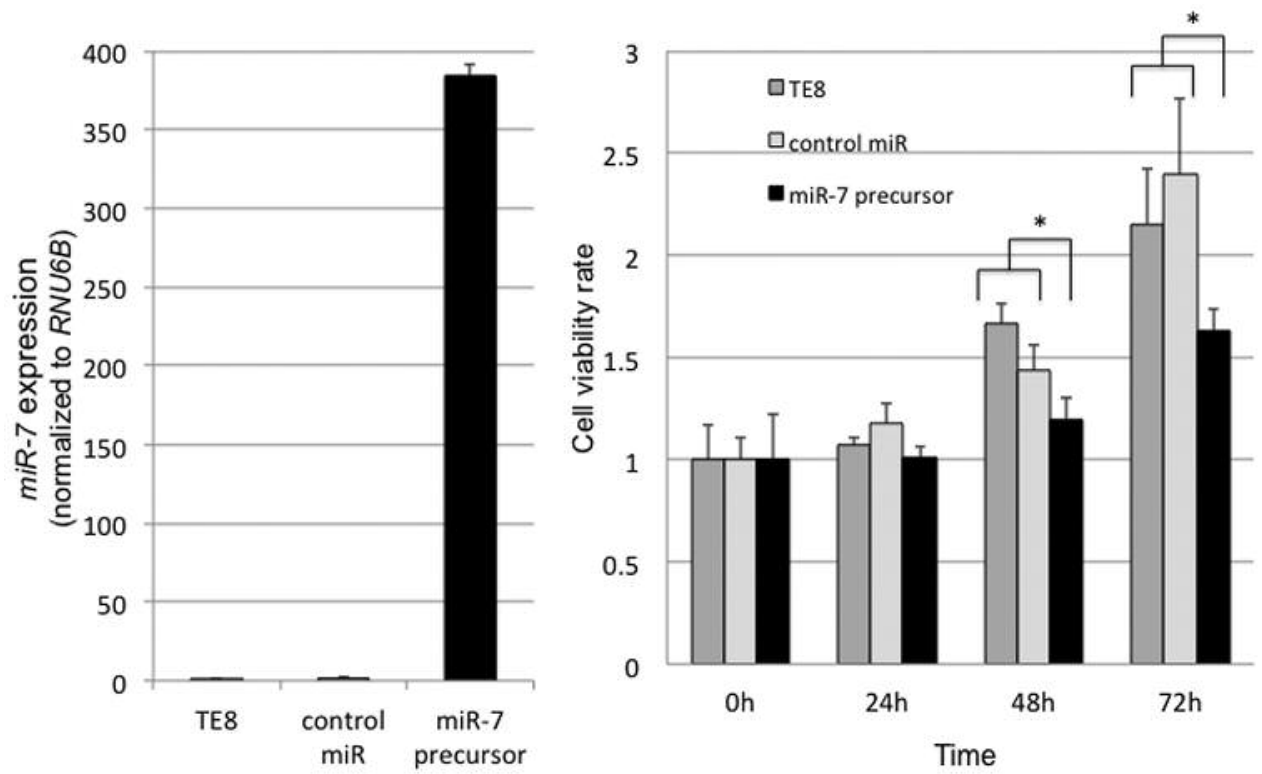

Figure 3. Proliferation potency of miR-7 precursor-transfected cells. A: Expression of miR-7 was shown to be significantly increased in miR-7 precursor-treated cells. B: The proliferation rate was reduced in miR-7 precursor-treated cells in comparison with that of control miR-treated cells. The data represent mean $\pm S D$. *Significantly different at $p<0.05$.

Table II. Results of univariate and multivariate analyses of clinicopathological Factors affecting the overall survival rate following surgery.

\begin{tabular}{|c|c|c|c|c|c|c|}
\hline \multirow[t]{2}{*}{ Clinicopathologic variable } & \multicolumn{3}{|c|}{ Univariate analysis } & \multicolumn{3}{|c|}{ Multivariate analysis } \\
\hline & $\mathrm{RR}$ & $95 \% \mathrm{CI}$ & $p$-Value & RR & $95 \% \mathrm{CI}$ & $p$-Value \\
\hline T Factor $(\mathrm{T} 1 / \mathrm{T} 2, \mathrm{~T} 3, \mathrm{~T} 4)$ & 0.4 & $0.15-0.89$ & $0.022 *$ & 0.57 & $0.2-1.33$ & 0.204 \\
\hline N Factor (negative/positive) & 0.4 & $0.19-0.87$ & $0.019 *$ & 0.6 & $0.25-1.3$ & 0.205 \\
\hline M Factor (negative/positive) & 0.6 & $0.29-1.25$ & 0.157 & 0.88 & $0.42-2.0$ & 0.76 \\
\hline Lymphatic invasion (negative/positive) & 0.21 & $0.01-0.99$ & $0.0489 *$ & 0.4 & $0.01-3.4$ & 0.428 \\
\hline Venous invasion (negative/positive) & 0.46 & $0.15-1.08$ & 0.0789 & 0.98 & $0.28-2.6$ & 0.969 \\
\hline$m i R-7$ expression (high/low) & 0.5 & $0.23-0.97$ & $0.0426 *$ & 0.48 & $0.18-0.86$ & $0.0389 *$ \\
\hline
\end{tabular}

RR: Relative risk, CI: confidence interval, ${ }^{*} p<0.05$.

increasing severity of clinicopathological factors. On in vitro analysis, we found that the proliferation of $m i R-7$ precursortreated ESCC cells decreased compared with the control cells.

We focused on miR-7 as an ESCC-specific miR, and initially predicted that $m i R-7$ might function as a tumour promoter in ESCC. The expression of $m i R-7$ was found to be increased in ESCC compared with normal tissue; however, patients with ESCC with low $m i R-7$ had a poorer prognosis than those with high expression of $m i R-7$. Similar to our findings in ESCC, previous study revealed that miR-7 expression in colorectal cancer cells was higher than that in normal cells but that the prognosis was worse in the patients with low expression than in those with high expression (14). On the other hand, downregulation of $m i R-7$ expression has been described in thyroid cancer and mesothelioma $(15,16)$. The detailed mechanism of miR-7 regulation in ESCC is unclear; however, other researchers have reported that E2F transcription factors regulate $m i R-7$ expression (17) and that USP18 negatively regulate $m i R-7$ expression (18). Moreover, Chuo et al. reported that the activation of epidermal growth factor receptor (EGFR) in lung cancer cells stimulated miR-7 expression via extracellular signal-regulated kinase (19). E2F and EGFR have been reported to be expressed in $\operatorname{ESCC}(20,21)$; this suggests that $m i R-7$ might be at least partially regulated by the activation of cancer-specific signals such as E2F and EGFR.

Down-regulation of miR-7 in ESCC samples was not associated with progression of existing clinicopathological factors; however, patients with miR-7 down-regulation had 
poorer prognosis than those with high miR-7 expression. $m i R$ 7 was reported to be suppressed in chemotherapy-resistant cancer cells (22-24). Moreover, Lee et al. described that $m i R$ 7 induction suppressed EGFR and protein kinase B expression, and induced increased sensitivity to radiation treatment in several cancer cell lines (25). Multiple targets have been identified for $m i R-7$, including EGFR, human epidermal growth factor receptor 2, Raf-1 proto-oncogene, multidrug resistance-associated protein 1 , focal adhesion kinase, insulinlike growth factor 1 receptor, B-cell lymphoma 2, and SATB homeobox 1, which are associated with therapeutic resistance and malignant potential in several cancer types $(14,23,26-30)$. In this study, we found that $m i R-7$ precursor treatment suppressed cell growth by ESCC cells. From these observations, we suggest that $m i R-7$ induction in patients with ESCC might be useful as a therapeutic strategy to overcome resistance to chemotherapy or radiation therapy, which are very important therapeutic tools for patients with ESCC.

In this study, we showed that $m i R-7$ treatment induced an anticancer effect on ESCC cells in vitro. This finding indicates that administration of $m i R-7$ to patients with ESCC might be a useful means of attacking the ESCC cells. In fact, previous reports have demonstrated that small RNAs administered systemically to humans were able to inhibit specific genes via an RNA interference mechanism, and these therapeutic strategies have attracted attention (31-35). Currently, the role of $m i R-7$ in the human circulatory system is not well understood; however, it has been reported that high levels of serum $m i R-7$ were associated with high sensitivity to chemoradiation in patients with ESCC (12) Administration of $m i R-7$ to the circulation might function as a sensitizer to chemotherapy or radiation therapy. In future, determination of an effective means to deliver miRs to cancerous tissue is an important task.

In conclusion, our data indicate that down-regulation of $m i R-7$ is associated with poor prognosis and reduced proliferative ability in ESCC. The level of $m i R-7$ in ESCC might be a powerful prognostic factor independent of existing clinicopathological factors. The regulation of miR7 could provide a promising novel possibility for targeted therapeutic strategies in ESCC.

\section{Conflicts of Interest}

None of the Authors has any conflict of interest to declare in regard to this study.

\section{Acknowledgements}

This work was supported in part by the following grants and foundations: Grants-in-Aid for Scientific Research from the Japan Society for the Promotion of Science (JSPS), grant numbers 26461969, 15K10129, and 15K10085; and Gunma University Initiative for Advanced Research (GIAR).

\section{References}

1 Malthaner RA, Wong RK, Rumble RB and Zuraw L: Neoadjuvant or adjuvant therapy for resectable esophageal cancer: a systematic review and meta-analysis. BMC Med 2: 35, 2004.

2 Gebski V, Burmeister B, Smithers BM, Foo K, Zalcberg J and Simes J: Survival benefits from neoadjuvant chemoradiotherapy or chemotherapy in oesophageal carcinoma: a meta-analysis. Lancet Oncol 8: 226-234, 2007.

3 Tepper J, Krasna MJ, Niedzwiecki D, Hollis D, Reed CE, Goldberg R, Kiel K, Willett C, Sugarbaker D and Mayer R: Phase III trial of trimodality therapy with cisplatin, fluorouracil, radiotherapy, and surgery compared with surgery alone for esophageal cancer: CALGB 9781. J Clin Oncol 26: 1086-1092, 2008.

4 Enzinger PC and Mayer RJ: Esophageal cancer. N Engl J Med 349: 2241-2252, 2003.

5 Parkin DM, Bray F, Ferlay J and Pisani P: Global cancer statistics, 2002. CA Cancer J Clin 55: 74-108, 2005.

6 Valencia-Sanchez MA, Liu J, Hannon GJ and Parker R: Control of translation and mRNA degradation by miRNAs and siRNAs. Genes Dev 20: 515-524, 2006.

7 Guo Y, Chen Z, Zhang L, Zhou F, Shi S, Feng X, Li B, Meng X, Ma X, Luo M, Shao K, Li N, Qiu B, Mitchelson K, Cheng J and $\mathrm{He} \mathrm{J}$ : Distinctive microRNA profiles relating to patient survival in esophageal squamous cell carcinoma. Cancer Res 68 : 26-33, 2008.

8 Ma Y, Wang B, Guo Y, Zhang Y, Huang S, Bao X and Bai M: Inhibition of $m i R-196 a$ affects esophageal cancer cell growth in vitro. Biomed Pharmacother 84: 22-27, 2016.

9 Ide S, Toiyama Y, Shimura T, Kawamura M, Yasuda H, Saigusa S, Ohi M, Tanaka K, Mohri Y and Kusunoki M: MicroRNA-503 promotes tumor progression and acts as a novel biomarker for prognosis in oesophageal cancer. Anticancer Res 35: 1447-1451, 2015.

10 Zhao K, Chen BJ, Chen ZG, Zhang YJ, Xu D and Liu Q: Effect of miR-503 down-regulation on growth and invasion of esophagus carcinoma and related immune function. Med Sci Monit 21: 3564-3569, 2015.

11 Fu HL, Wu DP, Wang XF, Wang JG, Jiao F, Song LL, Xie H, Wen XY, Shan HS, Du YX and Zhao YP: Altered miRNA expression is associated with differentiation, invasion, and metastasis of esophageal squamous cell carcinoma (ESCC) in patients from Huaian, China. Cell Biochem Biophys 67: 657668, 2013.

12 Dong W, Li B, Wang J, Song Y, Zhang Z, Fu C and Zhang P: Diagnostic and predictive significance of serum microRNA-7 in esophageal squamous cell carcinoma. Oncol Rep 35: 1449-1456, 2016.

13 Sobin LH and Wittekind CH: TNM Classification of Malignant Tumours, 6th edition. John Wiley \& Sons, Hoboken, New Jersey, USA, 2002

14 Suto T, Yokobori T, Yajima R, Morita H, Fujii T, Yamaguchi S, Altan B, Tsutsumi S, Asao $\mathrm{T}$ and Kuwano $\mathrm{H}$ : microRNA-7 expression in colorectal cancer is associated with poor prognosis and regulates cetuximab sensitivity via EGFR regulation. Carcinogenesis 36: 338-345, 2014.

15 Yue K, Wang X, Wu Y, Zhou X, He Q and Duan Y: microRNA7 regulates cell growth, migration and invasion via direct targeting of PAK1 in thyroid cancer. Mol Med Rep 14: 2127$2134,2016$. 
16 Guled M, Lahti L, Lindholm PM, Salmenkivi K, Bagwan I, Nicholson AG and Knuutila S: CDKN2A, NF2, and JUN are dysregulated among other genes by miRNAs in malignant mesothelioma -A miRNA microarray analysis. Genes Chromosomes Cancer 48: 615-623, 2009.

17 Tazawa H, Yano S, Yoshida R, Yamasaki Y, Sasaki T, Hashimoto Y, Kuroda S, Ouchi M, Onishi T, Uno F, Kagawa S, Urata Y and Fujiwara T: Genetically engineered oncolytic adenovirus induces autophagic cell death through an E2F1-microRNA-7-epidermal growth factor receptor axis. Int J Cancer 131: 2939-2950, 2012.

18 Duex JE, Comeau L, Sorkin A, Purow B and Kefas B: USP18 regulates epidermal growth factor (EGF) receptor expression and cancer cell survival via microRNA-7. J Biol Chem 286: 2537725386, 2011.

19 Chou YT, Lin HH, Lien YC, Wang YH, Hong CF, Kao YR, Lin SC, Chang YC, Lin SY, Chen SJ, Chen HC, Yeh SD and Wu CW: EGFR promotes lung tumorigenesis by activating $m i R-7$ through a RAS/ERK/MYC pathway that targets the ETS2 transcriptional repressor ERF. Cancer Res 70: 8822-8831, 2010.

20 Yamazaki K, Hasegawa M, Ohoka I, Hanami K, Asoh A, Nagano T, Sugano I and Ishida Y: Increased E2F-1 expression via tumour cell proliferation and decreased apoptosis are correlated with adverse prognosis in patients with squamous cell carcinoma of the oesophagus. J Clin Pathol 58: 904-910, 2005.

21 Mandard AM, Hainaut P and Hollstein M: Genetic steps in the development of squamous cell carcinoma of the esophagus. Mutat Res 462: 335-342, 2000.

22 Kastl L, Brown I and Schofield AC: miRNA-34a is associated with docetaxel resistance in human breast cancer cells. Breast Cancer Res Treat 131: 445-454, 2012.

23 Pogribny IP, Filkowski JN, Tryndyak VP, Golubov A, Shpyleva SI and Kovalchuk O: Alterations of microRNAs and their targets are associated with acquired resistance of MCF-7 breast cancer cells to cisplatin. Int J Cancer 127: 1785-1794, 2010.

$24 \mathrm{Wu}$ XM, Shao XQ, Meng XX, Zhang XN, Zhu L, Liu SX, Lin $\mathrm{J}$ and Xiao HS: Genome-wide analysis of microRNA and mRNA expression signatures in hydroxycamptothecin-resistant gastric cancer cells. Acta Pharmacol Sin 32: 259-269, 2011.

25 Lee KM, Choi EJ and Kim IA: microRNA-7 increases radiosensitivity of human cancer cells with activated EGFRassociated signaling. Radiother Oncol 101: 171-176, 2011.

26 Giles KM, Barker A, Zhang PM, Epis MR and Leedman PJ: MicroRNA regulation of growth factor receptor signaling in human cancer cells. Methods Mol Biol 676: 147-163, 2011.
27 Kong X, Li G, Yuan Y, He Y, Wu X, Zhang W, Wu Z, Chen T, Wu W, Lobie PE and Zhu T: MicroRNA-7 inhibits epithelial-tomesenchymal transition and metastasis of breast cancer cells via targeting FAK expression. PloS One 7: e41523, 2012.

28 Jiang L, Liu X, Chen Z, Jin Y, Heidbreder CE, Kolokythas A, Wang A, Dai Y and Zhou X: MicroRNA-7 targets IGF1R (insulin-like growth factor 1 receptor) in tongue squamous cell carcinoma cells. Biochem J 432: 199-205, 2010.

29 Xiong S, Zheng Y, Jiang P, Liu X and Chu Y: MicroRNA-7 inhibits the growth of human non-small cell lung cancer A549 cells through targeting BCL-2. Int J Biol Sci 7: 805-814, 2011.

30 McInnes N, Sadlon TJ, Brown CY, Pederson S, Beyer M, Shultze JL, McColl S, Goodall GJ and Barry SC: FOXP3 and FOXP3-regulated microRNAs suppress SATB1 in breast cancer cells. Oncogene 31: 1045-1054, 2012.

31 Davis ME, Zuckerman JE, Choi CH, Seligson D, Tolcher A, Alabi CA, Yen Y, Heifel JD and Ribas A: Evidence of RNAi in humans from systemically administered siRNA via targeted nanoparticles. Nature 464: 1067-1070, 2010.

32 Soifer HS, Rossi JJ and Saetrom P: MicroRNAs in disease and potential therapeutic applications. Mol Ther 15: 2070-2079, 2007.

33 Pecot CV, Calin GA, Coleman RL, Lopez-Berestein G and Sood AK: RNA interference in the clinic: challenges and future directions. Nat Rev Cancer 11: 59-67, 2011.

34 Elmen J, Lindow M, Schutz S, Lawrence M, Petri A, Obad S, Lindholm M, Hedtjarn M, Hansen HF, Berger U, Gullans S, Kearney P, Sarnow P, Straarup EM and Kauppinen S: LNAmediated microRNA silencing in non-human primates. Nature 452: 896-899, 2008.

35 Silvestri P, Di Russo C, Rigattieri S, Fedele S, Todaro D, Ferraiuolo G, Altamura $G$ and Loshivao P: MicroRNAs and ischemic heart disease: towards a better comprehension of pathogenesis, new diagnostic tools and new therapeutic targets. Recent Pat Cardiovasc Drug Discov 4: 109-118, 2009.

Received January 5, 2017

Revised February 19, 2017

Accepted February 21, 2017 